\title{
THE PHASE OUT OF CHLOROFLUOROCARBON (CFC) REFIRIGERANTS AND THE CURRENT STATUS OF RIPLACEMENTS IN THE REPUBLIC OF SOUTH AFRICA
}

\author{
F McGuinness \\ AECI Ltd
}

\section{INTRODUCTION}

Much of today's refrigeration and air-conditioning industry is based on chlorofluorocarbon (CFC) and hydrochlorofluorocarbon (CFC) refrigerants which were developed in the 1930's. Both these groups of refrigerants are now classified as "Ozone Depleting Substances".

The first concerns about the possible effect of CFCs on the earth's protective ozone layer were expressed by Rowland and Molina in 1974 in a paper published in the journal, Nature ${ }^{2}$.

Whilst the search for CFC replacements began in the mid-1970's, with no obvious and readily available candidates, and in the uncertainty about the actual role of CFCs in stratospheric chemistry and any potential effect on the ozone layer, little progress was made until the late 1980's.

The weight of evidence against CFCs did not really accumulate until the outputs from the Antarctic airborne expedition and the Ozone Trends Panel, both of whom reported in 1988, the year in which chemical companies like ICI started to call for total phase-out of CFCs. The concerns on the effects of these substances upon the ozone layer increased steadily during this period and led to the adoption, by international agreement of the Montreal Protocol on substances that deplete the Ozone Layer.

The Montreal Protocol on Substances that deplete the Ozone Layer is an international agreement, developed under the auspices of the United Nations Environment Programme (UNEP), to reduce the production and consumption of certain CFCs and Halons ${ }^{1}$. It was adopted by a diplomatic conference in Montreal on 16 September 1987, and it entered into force on 1 January 1989.

The Protocol is a complex agreement which, in addition to the control of production and consumption of CFCs and Halons, also contain provision for regular formal review and adjustment of the control measures based on scientific, environmental, technical and economic developments.

\section{MONTREAL PROTOCOL}

The original Montreal protocol controlled CFCs 11, 12, 113, 114 and 115, plus Halons 1211, 1301 and 2402. The revision in 1990 increased the numbers of controlled substances, adding all other fully halogenated CFCs with one, two or three carbon atoms (other CFCs), carbon tetrachloride, and 1,1,1-trichloroethane. The current control measures relating to the production and consumption of these substances are shown in Table I, It should be noted that the reference year for control of the CFCs and Halons is 1986, whilst for the other substances it is 1989.

New scientific developments and the technical options for CFC replacement were considered at a meeting of the Parties to the Protocol in London in June 1990. The outcome was a stringent revision of the Montreal Protocol control measures, with complete phase-out of the production and consumption of CFCs required by 1 January 2000. The Protocol's list of controlled substances was also extended. Significantly, it was also agreed that the Parties should meet again in 1992 to consider a possible earlier phase-out of CFCs.

At the June 1990 meeting in London, another very important decision was taken in respect of hydrochlorofluorocarbons (HCFCs) such as R22. It was recognised that HCFCs have a vital role to play in achieving CFC phase-out, even though the substances may have a minor effect on the ozone layer and must themselves eventually be replaced. HCFCs were therefore accorded the status of "Transitional Substances", they became the subject of a Resolution of the Parties regarding their use, but were excluded from controls under the terms of Protocol.

At the present moment this is the Montreal Protocol as it affects the Republic of South Africa. However there is nothing which prevents individual parties to the protocol from adopting more stringent phase out/phase down schedules and many countries have done so.

Revision of the protocol, scheduled for November 1992, is expected to advance CFC phase-out to 1995. This requires that not only must CFC replacement programmes for new equipment be accelerated but, with CFC shortages anticipated by 1994, it also means that the user industry must urgently address the issue of "retrofitting" existing equipment to prolong its useful economic lifetime.

HCFCs also seem destined to become 'Controlled Substances" in 1992 and be subject to phase-out possibly by the end of the century. This action reduces the number of candidate CFC replacements, and poses further challenges to industry in the development of HCFC replacements. 
TABLE I - Revised Montreal Protocol Control Measures, June 1990

\begin{tabular}{|c|c|c|c|c|c|}
\hline & CFCs & $\begin{array}{l}\text { Other } \\
\text { CFSs }\end{array}$ & Halons & $\begin{array}{l}\text { Carbon } \\
\text { Tetra- } \\
\text { chloride }\end{array}$ & $\begin{array}{l}1,1,1- \\
\text { Trichloro- } \\
\text { ethane }\end{array}$ \\
\hline Freeze & 1989 & - & 1992 & - & 1993 \\
\hline$-20 \%$ & - & 1993 & - & - & - \\
\hline$-\quad 30 \%$ & - & - & - & - & 1995 \\
\hline$-50 \%$ & 1995 & - & 1995 & - & - \\
\hline$-70 \%$ & - & - & - & - & 2000 \\
\hline$-85 \%$ & 1997 & 1997 & - & 1995 & - \\
\hline$-100 \%$ & 2000 & 2000 & 2000 & 2000 & 2005 \\
\hline
\end{tabular}

The formal meeting of the Parties to consider revision of the Montreal Protocol is scheduled for November 1992 in Copenhagen. In preparation for this meeting there has been a series of open-ended working group meetings to prepare proposals for both adjustments to existing control measures, and amendments to include newly controlled substances.

The first of these meetings was held in Geneva in April 1992 with a follow-up meeting in July 1992. Several formal proposals for adjustment of the CFC control measures were tabled. These included an $85 \%$ reduction in CFC production and consumption by 1 January 1994 and CFC phase-out dates of either 1 January or 31 December 1995.

At the July meeting, the Executive Director of UNEP tabled his own proposal for adjustment of the CFC control measures as a possible compromise between the numerous individual positions. This calls for a $75 \%$ reduction in 1986 levels of CFC production and consumption by 1 January 1994, and phase-out by 1 January 1996. This "compromises" proposal is illustrated graphically in Figure II.
It should be noted that such "adjustments" to the control measures of the substances originally listed in the 1987 Montreal Protocol are legally binding on all Parties and are not dependent upon re-ratification by Parties.

\section{TRANSITIONAL SUBSTANCES}

Hydrochlorofluorocarbons (HCFCs) are a group of substances which have many similar properties to the fully halogenated CFCs. Whilst both groups of substances contain chlorine, which is the key element in the chemistry concerning stratopheric ozone depletion, the HCFCs have much shorter atmospheric lifetimes than the CFCs with the result that they contribute much less chlorine to the stratosphere.

HCFC 22 (R22) is already widely used in refrigeration and air-conditioning equipment and in Table II it is interesting to compare it to CFC 12 in the respect of its atmospheric lifetime, Ozone Depletion Potential (ODP), and Halocarbon Greenhouse Warming Potential (HGWP).

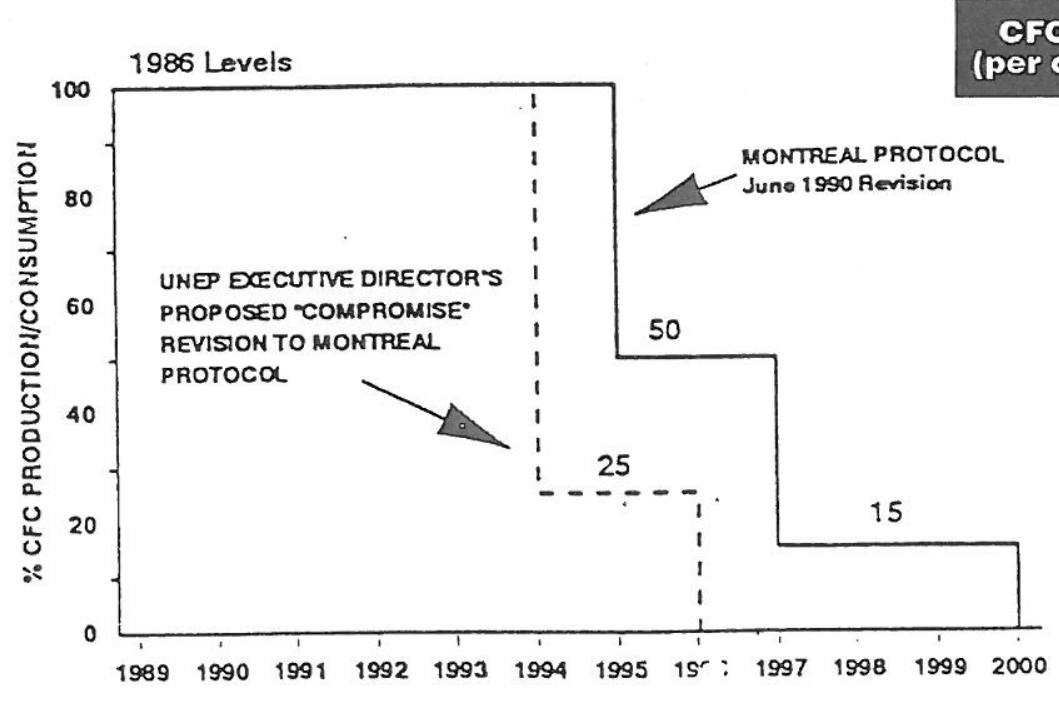


TABLE II - CFC 12 and HCFC 22 - Comparison of Atmospheric Lifetimes, Ozone Depletion Potential and halocarbon Greenhouse Warming Potential

\begin{tabular}{llllll}
\hline Product & Formula & $\begin{array}{l}\text { B. pt. } \\
\text { (deg. C) }\end{array}$ & $\begin{array}{l}\text { Atmospheric } \\
\text { Lifetime } \\
\text { years }\end{array}$ & $\begin{array}{l}\text { ODP } \\
\text { (Relative to CFC 11 = 1,0) }\end{array}$ \\
\hline CFC 12 & $\mathrm{CF}_{2} \mathrm{Cl}_{2}$ & -29.8 & 120 & 1.0 & \multicolumn{1}{c}{ HGWP } \\
HFCF 22 & $\mathrm{CHF}_{2} \mathrm{Cl}$ & -40.8 & 15.3 & 0.05 & 0.37 \\
HFC 134a & $\mathrm{CH}_{2} \mathrm{~F}-\mathrm{CF}_{3}$ & -26.2 & 16.0 & ZERO & 0.25 \\
\hline
\end{tabular}

The overall potential environmental impact of HCFC 22 is thus very substantially less than that of CFC 12 . This is true generally of the HCFCs and the vital role that they will pay in helping to achieve CFC phase-out was clearly recognised by the Parties to the Montreal Protocol. HCFCs were not therefore included in the protocol as controlled substances, a measure clearly aimed at encouraging their interim use as CFC replacements where no more environmentally acceptable alternative is available.

As a result of the recent scientific evidence indicating the ozone is being destroyed more rapidly than previously thought, the open-ended working group meeting of the Parties in April 1992 also made proposals for the control of HCFCs. The nature of the proposed controls suggested $\mathrm{HCFC}$ phase-out dates were diverse and wide ranging and so at the July 1992 meeting the UNEP Executive Director also tabled his own "compromise" proposals for the HCFC controls. These may be summarised as follows:

- an immediate "cap" on HCFC consumption at 3 per cent of 1986 ODP-tonnage of CFCs

- a positive or negative list of permitted or prohibited uses of HCFCs

- no differentiation between HCFCs on basis of different ODP

- phase-out of production and consumption of HCFCs for NEW equipment and products from 1 January 2000.

- phase-out of production and consumption of HCFCs for EXISTING equipment and products from 1 January 2005.

\section{SAFETY IN USE AND ENVIRONMENTAL ACCEPTABILITY}

A major feature of the introduction of any new chemical substance is the need to demonstrate its safety in use. The toxicological evaluation of a new chemical is a complex, expensive and time consuming exercise. There are clearly a number of advantages in collaborative studies to evaluate the toxicological properties of potential new fluorocarbon refrigerants to replace CFCs.

\section{PAFT}

A number of companies are therefore jointly funding toxicological studies within an industry consortium known as the "Programme for Alternative Fluorocarbon Toxicity Testing

PAFT I HCFC 123 and HFC 134A.

PAFT II HCFC 141B.

PAFT III HCFC 124 and HCF 125.

PAFT IV HCFC 124 and HCF 125.

PAFT V HFC 32.

A full programme of toxicological testing encompasses acute, sub-acute, reproductive, and chronic studies which typically takes up a period of 5 years. The PAFT studies are at differing stages of completion, from almost complete to just commencing. This paper confines itself to the PAFT I studies on HCFC 123 and HFC 134A.

Extensive studies on HCFC indicate that the occupational exposure limit for HCFC 123 will be significantly lower than that for CFC 11. A two generation reproduction study, a neurotoxcity study, and a metabolism study are in progress and are expected to be completed by the end of 1992.

Based on the exposure levels used in this two-year study, most PAFT companies, including ICI, have recommended that occupational exposure levels be reduced from the original $100 \mathrm{ppm}$ level (which was based on anaesthetic effects). Typically, the recommended maximum occupation exposure level is now $10 \mathrm{ppm}$ on an 8 hour time-weighted basis.

In the case of HFC 134a, the only outstanding results are those from the two year chronic study. The animal 
exposure phase was completed in November 1991, and the final report is expected around January 1993. All available tests results suggest that HFC 134a is a material of exceptionally low toxicity, and at least as safe as CFC 12 (which was much less tested and only at much lower concentrations).

PAFT has concluded that there is nothing to preclude the use of HFC 134a in general industrial applications provided that recommended industrial hygiene practices are observed. The recommended maximum occupation exposure limit for HFC 134a is $1000 \mathrm{ppm}$ by volume (8 hour TWA).

\section{AEAS}

The other requirement essential to the successful introduction of a CFC replacement is its environmental acceptability. Interested companies are therefore also collaborating in this field within an industry consortium called the "Alternative Fluorocarbon Environmental Acceptability Study" (AFEAS). Twelve companies initially contributed to preliminary studies to evaluate the potential environmental effects of HCFCs 141b, 123, 142b, 124, 22 , $225 \mathrm{ca} / \mathrm{cb}$ and HFCs 152a, 134a, 32 and 125, with special emphasis on:

- potential to effect stratospheric ozone

- potential to affect tropospheric ozone

- potential to contribute to model calculated global warming

- the degradation mechanisms and decomposition products

potential environmental effects of the decomposition products.

Results of this work are included in the 1989 report of the UNEP Science Panel' ${ }^{3}$. A year later, in November 1990, AFEAS joined together with the US Department of Energy to fund a major international study on the total contribution that these alternative fluorocarbons are likely to make to global climate change.

The atmospheric breakdown products of HFC 134a and HCFC 123 are principally hydrogen fluoride and carbon dioxide in amounts negligible compared with natural background levels. Trifluoroacetic acid is a probable atmospheric breakdown product of HCFC 123 and, to a limited extent, HFC 134a. The amounts produced are of no environmental significance.

\section{GLOBAL WARMING}

The calculated direct contribution to global warming from likely emissions of HFCs and HCFCs is less than $1 \%$ of the total contribution from all greenhouse gases. The indirect contribution from the energy consumption of refrigeration and air conditioning equipment is the dominant factor in global warming considerations. This means that the energy efficiency of systems using CFC replacements is critical. However, the AFEAS/DOE study also recognises that energy efficiency can be optimised to match or improve on existing CFC systems whichever $\mathrm{CFC}$ replacement is chosen.

The use of HFC 134a as a CFC 12 replacement in refrigeration and air conditioning equipment which has been optimised to achieve equal or improved energy efficiency to the CFC 12 systems, coupled with developments in containment technology, better equipment maintenance procedures, and recovery and recycling of the refrigeration means that HFC 134a can be regarded as posing negligible threat to the environment.

\section{RECOVERY, RECYCLING, AND RECLAIM}

\section{DEFINITIONS}

(Source: UNEP - report June 30, 1989)

RECOVERY - means to move refrigerant in any condition from a system and store it in an external container without necessarily testing or processing it in any way.

RECYCLING - means to clean up refrigerant for reuse by oil separation and single or multiple passes through moisture absorption devices, such as replaceable core filter-driers. This term usually implies procedures implemented at the filled job site or at a local service shop.

RECLAIM - means to reprocess refrigerant to new conditions, by means which may include distillation. May require chemical analysis of the contaminated refrigerant to determine that appropriate process specifications are met. This term usually implies the use of processes for procedures available only at a reprocessing or manufacturing facility.

Recovery and recycling of CFCs and air-conditioning sectors has significant potential both for reducing demand for new CFC and HCFC refrigerant production, and for reducing emissions of these substances to the atmosphere.

It should be noted that some countries have introduced regulations which mandate recovery and recycling. One example is the USA where every automobile airconditioning service workshop must employ CFC recovery and recycling equipment.

\section{PROGRESS WITHIN THE RSA IN ELUMINATING CFCs}

The baseline usage figure for all group 1 substances with the RSA is 12,500 ODP tons. It is from this that we take the \% reductions to meet the Protocol Steps. 
Current Usage within the RSA in 1992

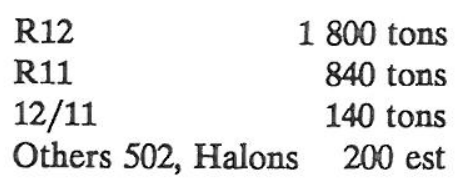

Usage by Industry

Aerosol

Foams:

Rigid Pu

Polystyrene

NIL

Refrigeration:

Automachine $\quad 200$

Auto Repair $\quad 600$

Domestic 250

Comfort $\quad 1200$

Mining $\quad 300$

Transport $\quad 100$

Industry Plans to move to ozone friendly Refrigerants.

Aeorosols - with the exception of medical - gone.

Foams - Polystyrene - converted to Pentane.

Rigid Pu - 1416 in 1994.

Automotive - Conversion between 1993 - 1995.

Mining - Conversion between 1993 - 1995.

Transport - Largely moving to R22.

Domestic - Between 1993 and 1994.

Comfort - Undecided.
From this it can be seen that the major area in which problems shall exist is that of refrigeration in which the conversion of the current equipment from R12 to the ozone friendly KLEA 134a is not progressing as well as could be hoped.

At the present time we therefore have a formidable task to meet the deadline of 1995 for the ending of R12 usage.

\section{CFC REPLACEMENTS}

It is generally accepted that any CFC replacement should meet the following criteria :

- non flammability

- low toxicity

- negligible environmental impact

- appropriate thermo-dynamic properties

- chemical stability

- compatibility with metals, elastomers and plastics

- high purity

- no energy penalty in use

- capable of manufacture at a reasonable cost

It is also desirable that its performance as a refrigerant should be similar to that of the material it is replacing ideally it should be a "drop in" replacement, and the cost of change should be minimal.

At present, HCFCs and HFCs alone are capable of meeting this demanding set of requirements.

The basic properties of potential direct replacements for CFC 11 and CFC 12 are shown in Table III and Table IV.

TABLE III - Potential Direct Replacements for CFC11

\begin{tabular}{llllll}
\hline Product & $\begin{array}{l}\text { B Pt } \\
{ }^{\circ} \mathrm{C}\end{array}$ & $\begin{array}{l}\text { Flamma- } \\
\text { bility }\end{array}$ & $\begin{array}{l}\text { Atmospheric } \\
\text { Lifetime }\end{array}$ & ODP & GWP \\
\hline CFC11 & +23.8 & No & 60 Years & 1.0 & 1.0 \\
HCFC123 & +27.1 & No & 1.6 Years & 0.02 & 0.02 \\
HCFC141B & +32.0 & Yes & 8.0 Years & 0.11 & 0.12 \\
\hline
\end{tabular}

TABLE IV - Potential Direct Replacements for CFC12

\begin{tabular}{llllll}
\hline Product & $\begin{array}{l}\text { B Pt } \\
{ }^{\circ} \mathrm{C}\end{array}$ & $\begin{array}{l}\text { Flamma- } \\
\text { bility }\end{array}$ & $\begin{array}{l}\text { Atmospheric } \\
\text { Lifetime }\end{array}$ & ODP & GWP \\
\hline CFC12 & -29.8 & No & 130 Years & 1.0 & 3.0 \\
HFC152a & -25.0 & Yes & 1.7 Years & Zero & 0.03 \\
HCFC134a & -26.2 & No & 16 Years & Zero & 0.25 \\
\hline
\end{tabular}


Both of the potential CFC 11 replacements are HCFCs and future control and phaseout under the Montreal Protocol should be noted.

HCFC 123 has been clearly demonstrated to be an excellent (technical) replacement for CFC 11 in centrifugual chillers, both in new equipment and for retrofitting existing equipment in order to prolong its useful economic lifetime; HCFC 123 has a very low ozone depletion potential and very low direct greenhouse warming potential.

HCFC $141 \mathrm{~b}$ is being considered as a CFC 11 replacement primarily in the manufacture of plastic foam for insulation purposes. This is of interest in a number of sectors of the refrigeration industry although $\mathrm{HCFC} 141 \mathrm{~b}$ is not being considered as a refrigerant. HCC $141 \mathrm{~b}$ has a significant ozone depletion potential in comparison to other HCFCs.

HFC 134a has clearly emerged as the refrigerant of choice to replacement CFC 12 due to the flammability of HFC 152a. HCF 134a contains no chlorine and therefore has no potential to deplete stratospheric ozone. It has a low "direct" greenhouse warming potential and in compressors and complete refrigeration systems optimised for HFC 134a duty, energy efficiencies matching the existing CFC 12 systems can be achieved.

HFC 134a is now the choice to replace CFC 12 in the following application areas ;

- Domestic, commercial, and industrial refrigeration

- Commercial air-conditioning

- Mobile air-conditioning

- Heat pumps

- Etc.

It is safe to use in refrigeration and air-conditioning applications so long as manufacturers' recommendations are followed. At present this means sensuring that exposures do not exceed $1000 \mathrm{ppm}$ on an 8-hour timeweighted average basis (of CFC 12, $1000 \mathrm{ppm}$ ) as was the case for R12.

HFC 134a is already available from a number of suppliers and significant additional production capacity is being installed to meet the demand created by the accelerated CFC 12-phase-out. ICI was the first company to manufacture HFC 134a on a commercial scale with the start-up of its European production facility in October 1990. ICI is also committed to a global supply strategy with production facilities in the USA and Japan schedule to come on stream in 1992 and 1993 respectively.

\section{HCFC REPLACEMENT}

As mentioned earlier, whilst HCFCs are presently recognised under the Montreal Protocol as "Transitional Substances" it is clear that they will be come "Controlled
Substances' when the Protocol is revised in November 1992. HCFCs may have an important role to play in achieving an early CFC phase-out, but only chlorine free HFCs with zero ozone depletion potential can be regarded as long term solutions for CFC replacement.

The phase-out of HCFCs also seems likely to be applications-related with either a positive list of permitted uses or a negative list of prohibited uses. A ban on the use of HCFC 22 in new equipment is effective in Germany from 2000. Proposed European Regulations will introduce immediate restrictions on the use of HCFCs by limiting the amounts allowed to be sold and restricting uses. The EEC also is considering banning the use of HCFCs where an HFC or zero ODP solution is available. Global phase-out of HCFCs can certainly be anticipated significantly ahead of the 2020 - 2040 time frame in the existing protocol and may be in the period 2000 2005.

It is equally clear from our experience with CFCs that legislation on HCFCs will be driven by the availability of alternatives.

Against this background, the search for chlorine free replacements for HCFCs has already begun. What is already apparent is that there is no obvious single candidate which meets all the essential criteria. The solution is seen to lie in a mixture of HFCs with tradeoffs necessary between energy efficiency, flammability and

direct greenhouse warming potential.

The search for alternatives to both CFCs and HCFCs is a top priority for ICI and extensive work on blends of "KLEA" 134a and "KLEA" 32 together with 'EMKARATE' refrigeration lubricants has resulted in the recent announcement of two new products :

TABLE VI - "KLEA" Blend 66-A Comparison with R22

$\begin{array}{lll}\text { Physical } & \text { R22 } & \text { "KLEA" Blend } 60 \\ \text { Properties } & & \end{array}$

\begin{tabular}{lll}
\hline $\begin{array}{l}\text { Ozone Depletion } \\
\text { Potential }\end{array}$ & 0.05 & 0 \\
\hline $\begin{array}{l}\text { Halocarbon Global } \\
\text { Warming Potential }\end{array}$ & 0.37 & 0.22 \\
\hline Toxicity OEL ppm & 1.000 & 1.00 (OEL) \\
\hline Flammability & No & No \\
\hline
\end{tabular}

For other low temperature refrigeration applications which presently use R502 and R500, mixtures of HFC 32, HFC 134a and HFC 125 are seen as the solution. 
Both products combine minimal environmental impact that is zero ozone depletion potential and low direct and indirect global warming impact - with high refrigeration capacity, and energy efficiency at least as good as that of the refrigerants they will replace. Additionally, the blends are non-flammable and it is anticipated that they will have a very low order of toxicity. Toxicological studies on HFC 32 and HFC 125 are in progress and final reports are expected by end 1993 .

TABLE V - "KLEA" Blend 60-A Comparison with $\mathrm{R502}$

\begin{tabular}{lll}
\hline $\begin{array}{l}\text { Physical } \\
\text { Properties }\end{array}$ & R502 & "KLEA" Blend 60 \\
\hline $\begin{array}{l}\text { Ozone Depletion } \\
\text { Potential }\end{array}$ & 0.23 & 0 \\
\hline $\begin{array}{l}\text { Halocarbon Global } \\
\text { Warming Potential }\end{array}$ & 4.0 & 0.35 \\
\hline $\begin{array}{l}\text { Toxicity OEL ppm } \\
\text { Flammability }\end{array}$ & No & 1.000 \\
\hline
\end{tabular}

\section{CONCLUSIONS}

- Global CFC phase-out now seems certain from 199, under the 1992 revision of the Montreal Protocol.

- HCFC controls are certain to be introduced with phase-out possible in the time frame $2000-2005$.

- Chlorine-free, zero ODP HFCs are the only long term solution to $\mathrm{CFC}$ and $\mathrm{HCFC}$ replacement.

- HFC 134a has zero ozone depletion potential and its contribution to global warming is minimal.
- Ester based lubricants are available for use with HFC 134a which offer total system performance comparable to CFC 12 /mineral oil.

- Optimised refrigeration systems demonstrate no energy penalty using HFC $134 a$ and ester lubricants. Further improvements can be anticipated.

- HFC $134 a$ is the refrigerant of choice to replace CFC 12.

- HFC 134a is available now.

- HFC 32 is the base for HCFC 22 and R 502, R 500 replacements.

- HCFC 22, R 502 and R 500 replacements could be commercially available by the mid 1990 's subject to a successful development programme.

\section{DISCLAIMER}

The views expressed in this paper are those of the author, and they do not necessarily represent the view of AECI Chemicals and Polymers Ltd.

\section{REFERENCE}

1. United Nations Environment Programme (UNEP), "Montreal Protocol on Substances that Deplete the Ozone Layer", Final Act, UNEP Nairobi, 1987.

2. Rowland, F S and Molina, J J Nature, 249, 8-10 (1974).

3. Alternative Fluorocarbon Environmental Acceptability Study (AFEAS), in Annex to United Nations Environment Programme (UNEP) Science Assessment, UNEP Nairobi, 1989.

("KLEA" and "EMKARATE" are trade marks, the property of ICI Chemicals \& Polymers Ltd). 